\title{
On Ultra-High Tensile Modulus by Drawing Single Crystal Mats of High Molecular Weight Polyethylene
}

\author{
Tetsuo Kanamoto, Akeharu Tsuruta, Koji TANAKA, \\ Masatami TAKEDA, and Roger S. PORTER* \\ Department of Chemistry, Science University of Tokyo, \\ Kagurazaka, Shinjuku-ku, Tokyo 162, Japan \\ * Materials Research Laboratory, \\ Department of Polymer Science and Engineering, \\ University of Massachusetts, Amherst, Mass. 01003, U.S.A.
}

(Received December 17, 1982)

\begin{abstract}
KEY WORDS Ultrahigh Molecular Weight Polyethylene / Single Crystal / Coextrusion / Drawing / High Draw Ratio / Ultra-High Modulus /
\end{abstract}

The modulus and strength of high density polyethylene (PE) increase steadily with deformation ratio (DR). ${ }^{1,2}$ However, the normal limit of DR achievable by a crystalline state deformation of melt-crystallized PE decreases with molecular weight $(\mathrm{MW})$ from $\sim 35$ for normal $\mathrm{MW}$ (NMWPE, MW $=1-3 \times 10^{5}$ ) to $5-10$ for ultrahigh MW (UHMWPE, MW $\left.\geq 10^{6}\right){ }^{3,4}$ Pennings et $a l^{5,6}$ have produced ultrahigh modulus and strength polyethylene morphologies by flowinduced crystallization and postdrawing of UHMWPE. Smith et al..$^{7,8}$ reported that the UHMWPE gel and dried gel prepared by quenching semi-dilute solutions could be drawn up to a high DR of 50. This highly-drawn UHMWPE exhibits markedly high tensile modulus (115 GPa) and strength $(4.7 \mathrm{GPa})$. In previous studies of the solid-state extrusion of $\mathrm{NMWPE}^{9}$ and UHMWPE, ${ }^{10}$ we have shown that drawability increased greatly for a single crystal morphology over that of a melt-crystallized spherulitic form. UHMWPE $\left(M_{v}=2 \times 10^{6}\right)$ in the form of sedimented mats of single crystals grown from dilute solutions $(\leq 0.2 \%)$ in xylene could be drawn up to a DR of 40 by tensile drawing at $90-130^{\circ} \mathrm{C}$ and to an extrusion draw ratio (EDR) of 110 by the crystalline statecoextrusion at $110^{\circ} \mathrm{C} .^{10}$

In this communication, we report the postdrawing of the previously extruded single crystal mats of
UHMWPE. This has produced ultraoriented films with a DR as high as 250 . Such superdrawn films exhibit extreme tensile moduli, up to $220 \mathrm{GPa}$, which approach the uncertain theoretical modulus reported for a perfect polyethylene crystal (240$340 \mathrm{GPa}) .^{11,12}$

\section{EXPERIMENTAL}

The UHMWPE and NMWPE used were Hizex Million $240 \mathrm{M}\left(M_{v}=2 \times 10^{6}\right.$, Mitsui Petrochemical Co., Ltd. $)$ and JX-20 $\left(M_{w}=6.7 \times 10^{4}\right.$, Mitsubishi Petrochemical Co., Ltd.), respectively. Solutiongrown crystals of UHMWPE were isothermally precipitated from dilute solutions $(0.05$ and $0.2 \%$ by weight) in xylene kept at $85^{\circ} \mathrm{C}$ over $20 \mathrm{~h}$. Sedimented mats of solution-grown crystals were obtained by slowly filtering the crystal suspension followed by drying in vacuo at $50^{\circ} \mathrm{C}$.

A two-stage drawing technique was used for drawing the solution-grown crystal mats of UHMWPE. For the first-stage drawing, the solidstate coextrusion technique developed by Porter $e t$ $a l^{13}$ was used. One or more mats were placed between two split billet halves of NMWPE and the assembly coextruded. Details for the extrusion of polyethylene single crystals are described elsewhere. ${ }^{9}$ For the second-stage, a conventional tensile drawing technique was used. Extrudates having 
a prior EDR 6, 12 and 25, 2-4 mm wide and 3$10 \mathrm{~mm}$ length, were drawn isothermally on a Tensilon tensile tester UTM-III over the $20-130^{\circ} \mathrm{C}$ range and at constant extension cross-head speeds of 4 to $40 \mathrm{~mm} \mathrm{~min}^{-1}$. The total draw ratio $\left(D_{\mathrm{t}}\right)$ after two-stage draw is defined as $\mathrm{DR}_{\mathbf{t}}=\mathrm{EDR} \times$ DR.

The tensile properties of doubly drawn films along the fiber axis were measured at room temperature and at a strain rate of $1 \times 10^{-3} \mathrm{~s}^{-1}$. The modulus was determined from the tangent to the stress-strain curve at a low strain $(<0.1 \%)$. The cross-sectional area of a sample $\left(10^{-1} \sim 10^{-3} \mathrm{~mm}^{2}\right)$ was calculated from the sample weight, length, and measured density.

\section{RESULTS AND DISCUSSION}

The X-ray analysis of as-prepared single crystal mats showed that lamallae of $145 \AA$ thickness were well oriented with the fold surface parallel to the mat surface and the molecular chains perpendicular to the surface. Although the maximum achievable $\mathrm{DR}_{\mathrm{t}}$ after the two-stage draw was slightly higher for the single crystal mat formed from a more dilute solution $(0.05 \%)$, the mat from $0.2 \%$ solution also exhibited excellent drawability. The most important parameter in achieving the ultimate draw, was the initial EDR. The highest $D_{R_{t}}$ was achieved from the EDR 6 extrudate which had the lowest EDR among those studied (EDR 6-25). Thus, the postdrawing of the EDR 6 extrudate will be emphasized.

Figure 1 shows nominal stress $v s$. strain curves recorded at constant temperatures over the 20 to $130^{\circ} \mathrm{C}$ range for the second-stage tensile drawing of the EDR 6 sample. It should be noted that the initial mats used in this work had poor deformability and could not be highly extended by tensile drawing below $90^{\circ} \mathrm{C}$, similar to the previous observation by Ishikawa et al. ${ }^{14}$ in drawing of NMWPE single crystal mats. However, prior extrusion of the mats to a low EDR greatly improved the subsequent tensile drawability, as depicted by the maximum attainable $\mathrm{DR}$ of $7\left(\mathrm{DR}_{\mathrm{t}}\right.$ of $\left.6 \times 7=42\right)$ at $20^{\circ} \mathrm{C}$ and $34\left(\mathrm{DR}_{\mathrm{t}}\right.$ of 200$)$ at $90^{\circ} \mathrm{C}$ for the postdrawing of an initial EDR of 6 . Furthermore, an extreme $\mathrm{DR}_{\mathrm{t}}$ of 250 was achieved by drawing the EDR 6 sample at near $115^{\circ} \mathrm{C}$. Such a high draw could not be attained for drawing of higher EDR extrudates $(E D R \geq 12)$. The draw rate in the range of 4 to 40

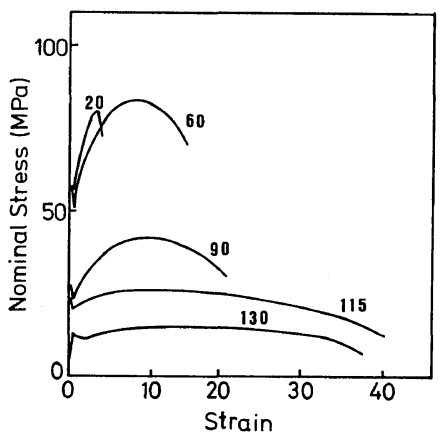

Figure 1. Nominal stress-strain curves for the postdrawing of the EDR 6 sample recorded at temperatures of 20 to $130^{\circ} \mathrm{C}$ and at a cross-head speed of 10 $\mathrm{mm} \min ^{-1}$. The initial gauge length was $3-4 \mathrm{~mm}$.

Table I. Tensile modulus of superdrawn UHMWPE films

\begin{tabular}{|c|c|c|}
\hline Draw temp & \multirow{2}{*}{$\begin{array}{c}\text { Total draw ratio } \\
(\mathrm{EDR} \times \mathrm{DR})\end{array}$} & \multirow{2}{*}{$\frac{\text { Tensile modulus }^{\mathrm{a}}}{\mathrm{GPa}}$} \\
\hline${ }^{\circ} \mathrm{C}$ & & \\
\hline & $6^{b}$ & 5 \\
\hline 20 & 21.5 & 40 \\
\hline 20 & 42 & 72 \\
\hline 60 & 64 & 99 \\
\hline 60 & 129 & 161 \\
\hline 90 & 72 & 87 \\
\hline 90 & 180 & 175 \\
\hline 115 & 60 & 115 \\
\hline 115 & 247 & 222 \\
\hline 130 & 66 & 102 \\
\hline 130 & 120 & 160 \\
\hline
\end{tabular}

a Dr. A. E: Zachariades in IBM Research Division at San Jose kindly measured the modulus of our sample with $\mathrm{DR}_{\mathrm{t}}$ of 160 and determined to be $170 \mathrm{GPa}$.

b Extrudate with EDR 6 used for the postdrawing.

$\mathrm{mm} \min ^{-1}$ had no appreciable effect on the maximum achievable $\mathrm{DR}_{\mathrm{t}}$.

The efficiency of draw was evaluated by the tensile properties. For the measurements, two ends, $\sim 2 \mathrm{~cm}$ long, of a drawn film of about $20 \mathrm{~cm}$ long was sandwitched with a small amount of super-glue between two pieces of sandpaper having a fine grain size. The sample with sandpaper was tightly fixed on cramps to avoid slippage during measurements and mounted on a tensile tester. The highly oriented samples always fractured at the edge of the cramp and at a low strain $(<1 \%)$. The apparent tensile 
strength at break in these measurements was in the range of 0.9 to $2.0 \mathrm{GPa}$ with no systematic change with $\mathrm{DR}_{\mathrm{t}}$. Thus, no reliable trend in strength was obtained and thus only the moduli are shown in Table I. The modulus of drawn samples increases with $\mathrm{DR}_{\mathrm{t}}$ at each temperature of draw $\left(T_{\mathrm{d}}\right)$, although $\mathrm{DR}_{\mathrm{t}}$ is significantly affected by $T_{\mathrm{d}}$. The $\mathrm{DR}_{\mathrm{t}}$ above 120 and a modulus $>150 \mathrm{GPa}$ could readily be achieved in the $T_{\mathrm{d}}$ range of 60 to $130^{\circ} \mathrm{C}$. The highest modulus recorded in this work is $222 \mathrm{GPa}$. This is about twice of the highest value reported for polyethylene, and approaches the lowest supposed theoretical estimate for the modulus of a perfect polyethylene crystal $(240-340 \mathrm{GPa}) .{ }^{11,12}$ The density of an initial single crystal mat was $0.974 \pm 0.001 \mathrm{~g} \mathrm{~cm}^{-3}$. It should be noted that the density of the highest modulus sample was $0.986 \pm 0.001 \mathrm{~g} \mathrm{~cm}^{-3}$, indicating the presence of $\sim 10 \%$ noncrystalline component even in such a high modulus sample.

In Figure 1, the yield and subsequent draw stress decrease, and the maximum achievable $D^{\circ}$ increases with $T_{\mathrm{d}}$ up to $115^{\circ} \mathrm{C}$. Above $130^{\circ} \mathrm{C}$, the achievable $\mathrm{DR}_{\mathrm{t}}$ decreases with increasing $T_{\mathrm{d}}$. The strain hardening phenomenon, usually observed for drawing semicrystalline polymers, is absent for the postdrawing of the EDR 6 sample. These features in the postdrawing are related to the specific morphology of the extrudate which allows the dramatically high $\mathrm{DR}_{\mathbf{t}}$. Although the role of the first-stage drawing by solid-state extrusion is not clear, the improvement of the crystal coherency during extrusion may play a part in improving the subsequent tensile drawability which allows the ultimate draw. Indeed, more recent studies suggest that the extensibility of an as-prepared single crystal mat sensitively depends on the coherency of the initial lamellae within a mat. Moreover, in some cases, a DR over 100 could be achieved by tensile drawing alone. More details of drawing single crystal mats of UHMWPE are currently under investigation.
In conclusion, a single crystal morphology of UHMWPE, grown from dilute solutions, has been shown to exhibit a high deformability. The improvement of drawing techniques has allowed us to extend UHMWPE up to an extreme DR of 250. Such highly oriented specimens exhibit ultra-high tensile moduli $\leq 222 \mathrm{GPa}$, approaching the lowest supposed theoretical value hitherto reported for a polyethylene crystal. No systematic nor reliable trends for tensile strength were obtained due to the lack of a suitable technique to measure the strength for these superdrawn, ultra-thin, uniform dimension, high modulus and strength films.

\section{REFERENCES}

1. W. G. Perkins, N. J. Capiati, and R. S. Porter, Polym. Eng. Sci., 16, 3 (1976).

2. G. Capaccio, T. A. Compton, and I. M. Ward, $J$. Polym. Sci., Polym. Phys. Ed., 14, 1641 (1976).

3. A. E. Zachariades, M. P. C. Watts, T. Kanamoto, and R. S. Porter, J. Polym. Sci., Polym, Letters Ed., 17, 485 (1979).

4. A. Kaito, K. Nakayama, and H. Kanetsuna, Polym. J., 14, 757 (1982).

5. A. Zwijnenburg and A. J. Pennings, Colloid Polym. Sci., 254, 868 (1976).

6. J. Smook, J. C. Torfs, P. F. van Hutten, and A. J. Pennings, Polym. Bull., 2, 293 (1980).

7. P. Smith, P. J. Lemstra, B. Kalb, and A. J. Pennings, Polym. Bull., 1, 733 (1979).

8. P. Smith, P. J. Lemstra, and H. C. Booij, J. Polym. Sci., Polym. Phys. Ed., 19, 877 (1981).

9. T. Kanamoto, E. S. Sherman, and R. S. Porter, Polym. J., 11, 497 (1979).

10. T. Kanamoto, A. Tsuruta, K. Tanaka, M. Takeda, and R. S. Porter, to be published.

11. I. Sakurada, T. Ito, and K. Nakamae, J. Polym. Sci., C, 15, 75 (1966).

12. T. Shimanouchi, M. Asahina, and S. Enomoto, $J$. Polym. Sci., 59, 93 (1962).

13. P. D. Griswold, A. E. Zachariades, and R. S. Porter, Polym. Eng. Sci., 18, 861 (1978).

14. K. Ishikawa, K. Miyasaka, and M. Maeda, J. Polym. Sci., A-2, 7, 2029 (1969). 